\title{
Social Distancing and Lockdown Due to COVID-19 Pandemic Will not Work in Africa
}

\author{
Faisal Muhammad (iib ${ }^{1,2, *}$ \\ ${ }^{1}$ Department of Public Health, Faculty of Allied Health Sciences, Daffodil International University, Dhaka, Bangladesh \\ ${ }^{2}$ Department of Social Work, School of Liberal Arts and Social Sciences, University of Information Technology and Sciences, Dhaka, Bangladesh \\ "Corresponding author: B.Sc, MPH, MSS, Research Associate, Department of Public Health Daffodil International University (DIU) 102 \& 102/1 Shukrabad, Mirpur Road \\ Dhanmondi, Dhaka-1207, Bangladesh. Email: fokkanya@yahoo.com \\ Received 2020 April 28; Accepted 2020 April 28.
}

Keywords: COVID-19, Pandemic, Social Distancing, Lockdown, Africa

\section{Dear Editor,}

Globally, as a result of the COVID-19 pandemic, many countries have implemented social distancing measures; because it was predicted that the implementation of effective social distancing policy could significantly reduce the coronavirus-related mortality worldwide. The first confirmed case of COVID-19 in Africa was reported in Egypt on February 14, 2020. Most African countries have imposed lockdown measures, which is stricter than in many countries across the globe.; Since most of the people in this region are daily laborers, Social distancing and lockdowns in African countries is a big challenge. Although people want to be safe from the illness, the majority of people in Africa cannot work from home. The lockdowns can cause problems, chaos, violence, and high levels of contact between people, which in turn can exacerbate the spread of coronavirus (1). African countries have taken several measures to encourage social distancing by focusing on borders and travel restrictions, school closures, and bans on large gatherings (2). In the African region, full lockdowns will never be an option; however, the policymakers need to provide clear guidance and awareness regarding social distancing. Although social distancing lowers the risk of contracting COVID-19, it limits the people's economic opportunities as well. Since social distancing prevents individuals from doing outdoor jobs and generating income for daily activities, it can lead to malnutrition, hunger, and other life-threatening health problems (1).

In Africa, effective social distancing is not possible because of overcrowding and poor sanitation. Many people in Africa live in poverty, on a hand-to-mouth basis. It was reported that over 330 million, out of a total population of 1.3 billion Africans, already live in hunger (3). Currently, many countries in Africa have witnessed extraordinary economic growth and development. The COVID-19 pandemic can be a threat to the future of African countries. Most African people grow their own food, and social distancing is easy to adhere for them; because they usually live in a house neighboring their farmlands. Most of the hospitals in African countries have very few intensive care unit (ICU) beds and lack well-trained staff. Most African countries are categorized among the countries with the lowest healthcare staff in the world (4). In Africa, there are also a considerable number of street children. It was estimated that there are about 100 million street children, worldwide (5). In the current situation, food is the main problem because hotels and eating places where they would normally get food have closed down. Governments, companies, and NGOs should donate food for their survival (5). In my opinion, communication will be a crucial pillar of any prevention strategy in Africa. As African countries continue to adapt their responses to COVID-19, the governments need to find the easiest way to help their citizens. In most of the local areas in Africa, people can grow their own food. However, people living in cities are in a difficult situation; because all the workplaces are locked down. Policymakers should think twice and care about sub-Saharan Africa for humanitarian reasons.

\section{Footnotes}

Conflict of Interests: The author has no conflict of interest.

Funding/Support: None. 


\section{References}

1. Mobarak AM, Barnett-Howell Z. Poor Countries Need to Think Twice About Social Distancing. 2020, [cited April, 15 2020]. Available from: https://foreignpolicy.com/2020/04/10/poor-countries-socialdistancing-coronavirus/.

2. Chibwana C. Opinion: Lockdowns won't work- the case for strategic social distancing policies in Africa. 2020, [cited April 15, 2020]. Available from: https://www.devex.com/news/opinion-lockdowns-won-t-workthe-case-for-strategic-social-distancing-policies-in-africa- 96902.

3. Lempinen E. Africa faces grave risks as COVID-19 emerges, says Berkeley economist. 2020, [cited April 15, 2020]. Available from https://news.berkeley.edu/2020/03/31/africa-faces- grave-risks-ascovid-19-emerges-says-berkeley-economist/.

4. Roberts K, Broadbent A, Smart BTH. Social distancing can be impossible because of overcrowding and poor sanitation. 2020, [cited April 16, 2020]. Available from: https://nationalinterest.org/blog/buzz/whystrict-policing-during-lockdown-wont-work-countries-highlevels-inequality- 144547.

5. The Guardian. 'Will we die of hunger?' How Covid-19 lockdowns imperil street children. 2020, [cited April 15, 2020]. Available from: https:// www.theguardian.com/global-development/2020/apr/15/will-wedie-of-hunger-how-covid-19-lockdowns-imperil-street-children. 